\title{
Diamonds from Myanmar and Thailand: Characteristics and Possible Origins
}

\author{
Griffin, W.L. ${ }^{1,2}$, Win, T.T. ${ }^{2}$, Davies, R. ${ }^{2}$, Wathanakul, P. , Andrew, A. and Metcalfe, I \\ 1. GEMOC National Key Centre,Macquarie University, NSW 2109, Australia \\ 2. CSIRO Exploration and Mining, North Ryde, NSW 2113, Australia \\ 3. Faculty of Science, Kasetsart University, Bangkok, Thailand \\ 4. CSIRO Div. of Petroleum Exploration, North Ryde, NSW 2113, Australia \\ 5. Div. of Earth Sciences, University of New England, Armidale, NSW 2350, Australia
}

Alluvial diamonds with no obvious sources ("headless placers") are found in several areas of Australasia, including Myanmar, southern Thailand (Phuket), Sumatra, Kalimantan and eastern Australia (Fig. 1). These deposits occur in relatively young geological terrains, in contrast to the Archean or Proterozoic terrains that host most primary diamond deposits and their associated alluvial workings.

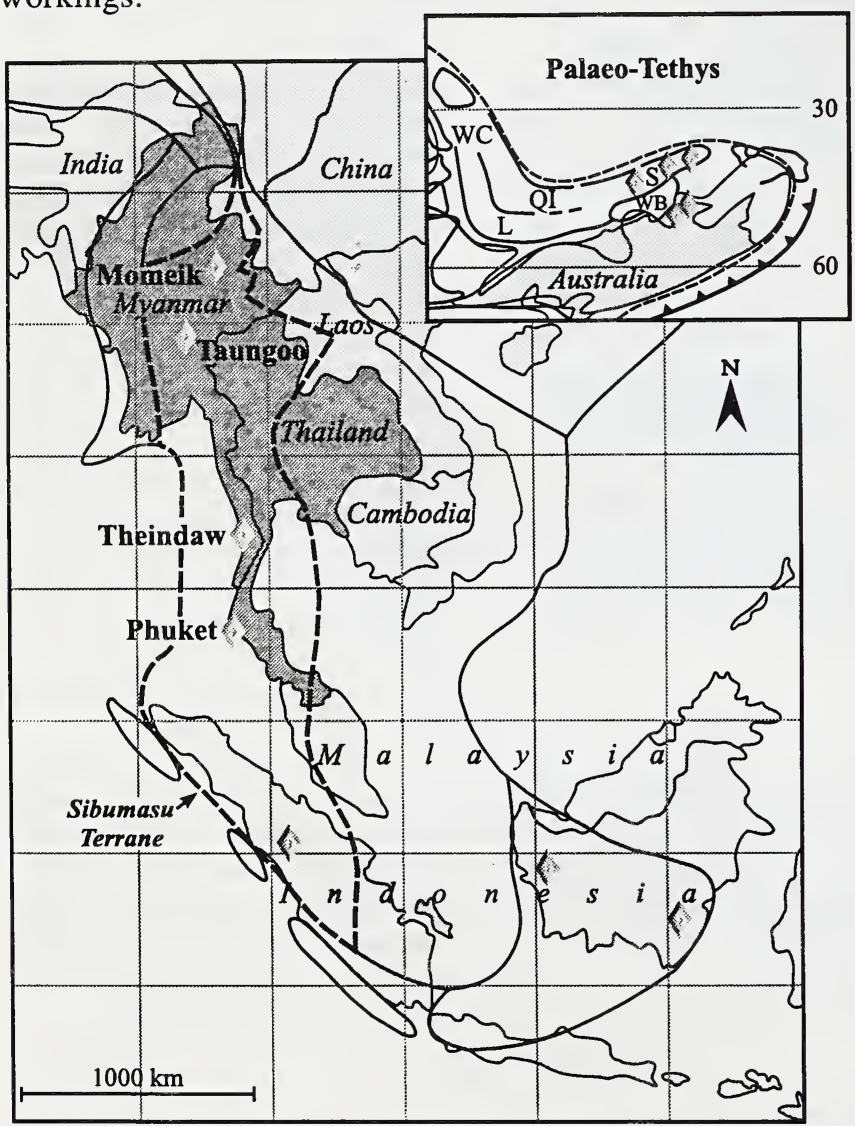

Fig. 1. Distribution of alluvial diamonds in SE Asia. Sibumasu terrane outlined by thick dashed line.

Inset: Permian plate reconstruction, showing location of Sibumasu (S) and Western Burma (WB) terranes adjacent to NW Australia.
Significant quantities of diamonds have been recovered from two areas in Myanmar, Momeik in the northern part of the country, and Theindaw in the southern part, and from the PhuketTakuapa area of SW Thailand. Smaller quantities have been found in several other localities, notably in the Taungoo-Htantabin area of Myanmar. The Momeik diamonds are recovered during mining of gemstone gravels; the Theindaw and Phuket diamonds are by-products of tin dredging. To understand the origin of these enigmatic diamonds and to provide an improved exploration model, we are carrying out detailed studies of the morphology, mineral inclusions, internal growth structures and growth history, nitrogen concentration and aggregation state, and carbon isotopic composition of diamonds from Myanmar, Thailand and eastern Australia.. We have examined $>40$ stones from Phuket, $>110$ from Theindaw and $>25$ from Momeik; these range in size from $<0.1 \mathrm{ct}$ to 3.5 $\mathrm{ct}$, averaging ca $0.2 \mathrm{ct}$. While there are differences among the samples from different areas, the small sample size means these may not be representative, and the similarities among the samples are striking. They are therefore described together here. More detailed data are given by Win et al. (1998) and Wathanakul et al. (1998). 
Most of the diamonds from both Myanmar and Thailand have rounded forms and smooth, often glossy surfaces; octahedral stones with planar faces are rare. Approximately $90 \%$ of the stones from all areas fall in resorption categories 1 or 2 (dodecahedral or tetrahexahedroidal) of McCallum et al. (1994). Fewer than 10\% of the stones retain traces of octahadral form (categories 3 to 4); 10-25\% of the sample consists of twinned crystals, including flattened macles which now are heavily resorbed. Studies of internal structure by UV photoluminescence, cathodoluminescence (CL) and birefringence reveal octahedral growth zoning in most diamonds. This shows that the present strongly rounded forms are secondary, and reflect resorption of the diamonds at high temperature, probably in the host magma. This resorption has removed $25-60 \%$ of the original mass of most stones, and produced a wide range of surface microstructures visible in SEM images. Lamination lines, reflecting plastic deformation, occur on ca $70 \%$ of the Myanmar stones and $80 \%$ of the Phuket stones examined; more than one set is commonly present. Aside from lamination lines, the most common surface features are shield-shapped laminae, followed by hillocks, etch pits and rare trigons. $>50 \%$ of the stones have striking glossy surfaces, which appear smooth even at high magnification in the SEM. Features reflecting corrosion in near-surface environments include corrosion pits and ruts. Abrasion during alluvial transport is reflected in a high proportion of broken stones, abundant percussion scars and frosted edges, and rhombic cracking. Brown (rarely green) spots, probably caused by radiation from nearby U,Th-rich minerals, occur on $45 \%$ of the stones examined. These spots, and others not seen in ordinary light microscopy, appear on CL images as black spots fringed with yellow; ca $60 \%$ of the Myanmar stones, and $70 \%$ of the Thai stones studied show this feature.

Some stones are colourless, but most range from yellow through brown (the dominant colour) to deep reddish-brown (cognac); rare pink stones are known, especially from the Phuket area. The brown colours, in particular, are associated with plastic deformation, seen as lamination lines on resorbed surfaces. Many stones thus show a characteristic oscillatory blue-yellow CL pattern, and a high proportion show strong yellow CL colours. This yellow colour also is seen along deformation planes, and appears to be responsible for the yellow CL colour of nitrogen-rich zones within the diamonds. Most diamonds show blue or yellow luminescence under UV light, and several show blue cores and yellow rims. This latter feature, and the yellow or yellow-blue oscillatory CL pattern, are uncommon in kimberlitic diamonds but have been observed in stones from the Argyle lamproite in NW Australia.

\section{Chemical Features}

Studies of syngenetic mineral inclusions are in progress; those identified thus far are mainly of the peridotitic paragenesis, and include olivine, chromite, Cr-pyrope and native iron. Infra-red

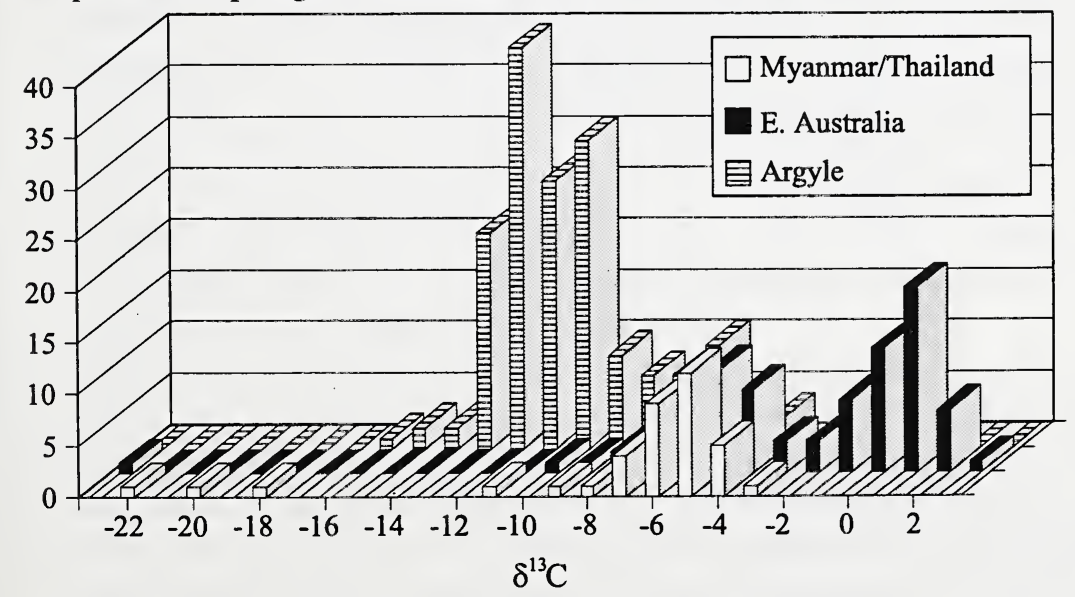

Fig. 2. Carbon-isotopic composition of diamonds from Myanmar and Thailand, compared to diamonds from Argyle and eastern Australia (Davies et al., this volume). spectroscopy (FTIR) studies show that ca $15 \%$ of the Theindaw diamonds have very low $\mathrm{N}$ contents (Type II diamonds); one Type II diamond has been found in the Phuket samples and one at Momeik. In the other stones, $\mathrm{N}$ contents range up to $>1000 \mathrm{ppm}$, and average ca $500 \mathrm{ppm}$. Nitrogen aggregation to Types $\mathrm{IaB}$ ranges between $10 \%$ and $80 \%$ and averages ca $30 \%$. In general aggregation state and 
$\mathrm{N}$ content are positively correlated, but the correlation is poor. Many stones with high aggregation states, including many with low $\mathrm{N}$ contents, show extensive plastic deformation, which is believed to have enhanced the rate of aggregation.

Carbon isotope compositions of 37 Myanmar and Thailand diamonds show a distribution similar to other diamonds worldwide. All values of $\partial^{13} \mathrm{C}$ from Phuket fall between -3 and $-7 \% o$. Most of the data from Myanmar also fall in this peak, but 3 values spread from -7 to $-11 \%$, and 3 from -17 to $-22 \%$. This pattern is distinct from that of Argyle diamonds, which show a major peak between -8 and $-13 \%$, and from that of morphologically similar diamonds from eastern Australia (Davies et al., this volume).

\section{Possible Origin(s) of the diamonds from Myanmar and Thailand}

Our data indicate that the Myanmar and Thailand diamonds are derived from "normal" mantle sources, and probably were brought to the surface by kimberlitic or lamproitic magmas. They are not derived from metamorphic rocks, and there is no evidence for a relation to subduction processes. The high incidence of plastic deformation, yellow-blue oscillatory CL and "reversed" UV zonation, as well as the highly polished resorbed surfaces, are more characteristic of diamonds from lamproitic sources, rather than kimberlitic sources. Features of breakage, surface wear and abundance of radiation-damage spots attest to long periods of residence in alluvial systems.

The Myanmar-Thailand-Sumatra alluvial diamond localities lie within the Sibumasu terrane (Metcalfe, 1996). Paleogeographic reconstructions (Fig. 1) suggest that the terrane was detached from NW Australia in Mesozoic time, and drifted northward to become part of SE Asia. Its original location lay west of the Kimberley region with its known diamond deposits. This region was glaciated in Permian time, and Permian glacial sediments are found from Sumatra to northern Myanmar, especially in connection with the Phuket and Theindaw diamond occurrences. We suggest that the Myanmar-Thailand diamonds are derived from primary sources on the Australian continent, or in the Western Burma terrane while it was still a part of that continent, and secondarily from the Permian glacial sediments. However, we cannot exclude derivation from primary (lamproitic?) sources within the transported terrane. The Kalimantan diamonds lie in another terrane with a different origin; like the E. Australian diamonds, they may be directly or indirectly related to subduction processes (Griffin et al., 1998).

\section{References}

Griffin, W.L., O'Reilly, S.Y. and Davies, R.M. 1998. Rev. Econ. Geol. (in press)

Metcalfe, I. 1996. Aust. Jour. Earth Sci. 43, 605-623.

Wathanakul, P., Win, T.T., Davies, R. and Griffin, W.L. 1998. Jour. SE Asia Geology, subm.

Win, T.T., Davies, R. and Griffin, W.L. 1998. Jour. SE Asia Geology, subm. 